\title{
TITLE:
}

\section{Underwater microdischarge in arranged microbubbles produced by electrolysis in electrolyte solution using fabric-type electrode}

\section{$\operatorname{AUTHOR(S):~}$}

Sakai, Osamu; Kimura, Masaru; Shirafuji, Tatsuru; Tachibana, Kunihide

\section{CITATION:}

Sakai, Osamu ... [et al]. Underwater microdischarge in arranged microbubbles produced by electrolysis in electrolyte solution using fabric-type electrode. APPLIED PHYSICS LETTERS 2008, 93(23): 231501.

\section{ISSUE DATE:}

2008-12-08

URL:

http://hdl.handle.net/2433/84570

\section{RIGHT:}

Copyright 2008 American Institute of Physics. This article may be downloaded for personal use only. Any other use requires prior permission of the author and the American Institute of Physics. 


\title{
Underwater microdischarge in arranged microbubbles produced by electrolysis in electrolyte solution using fabric-type electrode
}

\author{
Osamu Sakai, ${ }^{1, a)}$ Masaru Kimura, ${ }^{1}$ Tatsuru Shirafuji, ${ }^{2}$ and Kunihide Tachibana ${ }^{1}$ \\ ${ }^{1}$ Department of Electronic Science and Engineering, Kyoto University, Kyoto-daigaku Katsura, \\ Nishikyo-ku, Kyoto 615-8510, Japan \\ ${ }^{2}$ Innovation Collaboration Center, Kyoto University, Kyoto-daigaku Katsura, Nishikyo-ku, \\ Kyoto 615-8510, Japan
}

(Received 2 September 2008; accepted 6 October 2008; published online 8 December 2008)

\begin{abstract}
Pulsed microdischarge was generated in microbubbles produced by electrolysis in an electrolyte solution without external gas feed by using a fabric-type electrode. The electrode structure not only allowed low-voltage ignition of the atmospheric-pressure discharge in hydrogen or oxygen containing microbubbles but also worked effectively in producing and holding the bubbles on its surface. The generation of reactive species was verified by optical emissions from the produced microplasmas, and their transport into the solution was monitored by the change in hydrogen concentration. (C) 2008 American Institute of Physics. [DOI: 10.1063/1.3006348]
\end{abstract}

Plasmas in or on liquid are promising for advanced reactive phases that have not been achieved in a usual aqueous solution. They may contribute to a number of chemical reactions taking place in liquids; inorganic and organic reactions in chemical plants might be promoted by radical species produced by plasmas, and a number of surface treatments of biological materials in liquids will be activated by charged particles as well as radical species. Several reports showed that plasmas generated underwater participated in inorganic and organic reactions, ${ }^{1-3}$ and further controllability of supply and transport of reactive species by plasmas will enhance possibilities of sophisticated plasma processes in aqueous solutions.

Several reports on plasma generations in or on liquid so far were given on plasmas with external gas feed, plasmas of vaporized water, and plasmas of ambient air, and so radical production was mainly from $\mathrm{H}_{2} \mathrm{O}$ itself or ambient $\mathrm{N}_{2}$ and $\mathrm{O}_{2}$; they included reactive species in a significant amount, but there were little controllable parameters of gas composition in those cases. Here, we show hydrogen or oxygen plasma generation in aqueous solution. Plasmas include one-majority species (hydrogen or oxygen) with water vapor as a minority species, which has been briefly reported previously. ${ }^{4}$

One of the unique points of our method is that hydrogen and oxygen are not supplied from the external gas feed but are generated through electrolysis in an efficient-dilute solution, and so no gas container is required for the equipment. Hydrogen and oxygen can be supplied selectively and separately. Another point is that plasmas are generated by a "fabric"-type electrode, ${ }^{5,6}$ which sustains low-voltage atmospheric-pressure discharges and has a fine structure holding microbubbles on its surface. This fact enables us to arrange hydrogen or oxygen microbubbles on its surface in an adjustable way. An assembly of microbubbles containing microplasmas has a larger surface exposed to liquid than one bulk plasma, which can be the third advantage for us.

In this report, we demonstrate hydrogen and oxygen microplasma generations in microbubbles in an electrolyte. Hy-

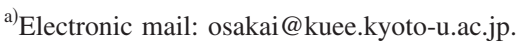

drogen bubbles were produced on a cathode electrode through electrolysis. Bipolar voltage was applied to an insulated wire that was attached to the microbubbles and countered to grounded wire electrode, which worked as the cathode for the electrolysis, and hydrogen microplasmas were observed with atomic hydrogen emissions. On the other hand, when oxygen microbubbles were produced on the grounded wires that also worked as the anode electrode in electrolysis, oxygen plasmas were generated in the oxygen microbubbles, which was verified by atomic oxygen emission. In the case of hydrogen microplasmas, $p \mathrm{H}$ values were measured to estimate net transport of $\mathrm{H}$ ions and/or atoms to the solution, where $p \mathrm{H}=-\log a_{\mathrm{H}^{+}}$and $a_{\mathrm{H}^{+}}$is the activity of $\mathrm{H}^{+}$ions.

An electrode system installed in aqueous solution (50 $\mathrm{cm}^{-3}$ in volume) is shown in Fig. 1. The electrode was in fabric form, which was originally used for generation of integrated microplasmas at atmospheric pressure. ${ }^{5,6}$ One electrode as weft lines was composed of bare stainless steel wires of $200 \mu \mathrm{m}$ in diameter, and the other electrode as warp lines was formed by insulated wires with ethylene tetrafluoroethylene with a thickness of $250 \mu \mathrm{m}$, which served as a dielectric barrier of discharge current. Fabric electrodes with total area of $4.0 \mathrm{~cm}^{2}$ were weaved by a manual loom (SET-100, Epitech Inc.). The weft lines of stainless steel wires were also connected to a stainless-steel plate through a low-voltage dc power supply, which produced current for electrolysis; the wires became cathode when the electric potential of the wires was set to be slightly lower than that of

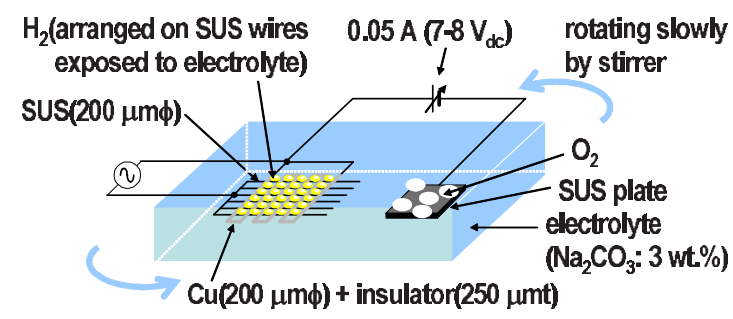

FIG. 1. (Color online) Schematic view of the experimental setup for generation of hydrogen or oxygen microbubbles and microplasmas in aqueous solutions. 
(a)

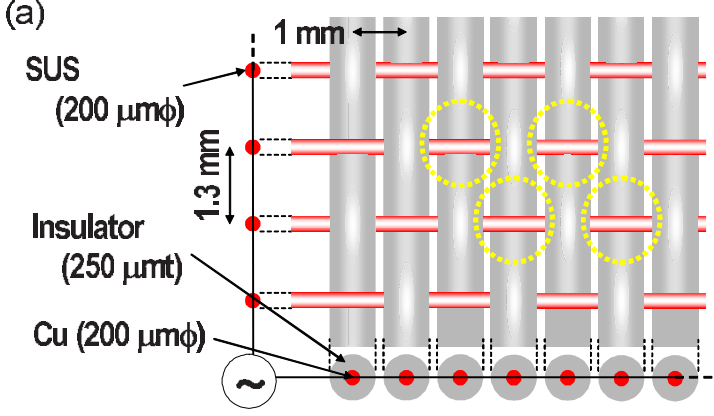

(b)
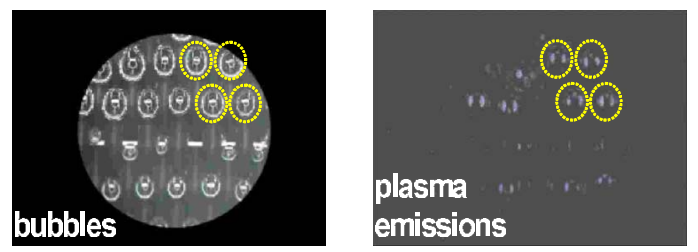

FIG. 2. (Color online) (a) Enlarged schematic view of a fabric-type electrode. (b) Microscope views of hydrogen microbubbles arranged on a fabrictype electrode, and visible emission from microplasmas generated in bubbles. Dotted circles are indicators for the same positions.

the plate, for instance. When the dc power supply was turned on, microbubbles were generated on the wires and became larger gradually. The approximate size (in several hundreds of microns in our experiment) can be controlled by adjusting the turn-on time of the dc power supply. The bubbles generated on the plate electrode were larger in size $(2-4 \mathrm{~mm}$ in diameter) than the microbubbles. $\mathrm{Na}_{2} \mathrm{CO}_{3}$ in 3 wt $\%$ was used as a solute, and so the solution exhibited a base property.

Figure 2(a) shows microbubbles stored on the fabrictype electrode, where hydrogen bubbles were formed when the bare wires were negatively biased as the cathode in the electrolysis. Since the exposed points of the wires to the solution were completely aligned, the generated hydrogen bubbles were also arranged on the surface of the fabric-type electrode. The microbubbles also made contact with the insulated wires, and so microplasmas were generated when a high voltage of more than $1.3 \mathrm{kV}_{0 \mathrm{p}}$ at $10 \mathrm{kHz}$ was applied to the insulated wires by an alternative-current power amplifier (Trek, Model 10/40A), as shown in Fig. 2(b). Discharge emission was observed in a narrow space between the insulated and bare wires.

Discharge characteristics were investigated using Lissajous curves, which were plotted using accumulated charges deduced from a flowing current as a function of the applied voltage. Figure 3 shows Lissajous curves in the cases at 1 and $3 \mathrm{kV}_{0 \mathrm{p}}$ ac voltage. In the case of the bipolar voltage at $1 \mathrm{kV}_{0 \mathrm{p}}$, which was less than ignition voltage, no hysteresis was observed. In the case of $3 \mathrm{kV}_{0 \mathrm{p}}$, however, a hysteresis curve was obtained, which means that discharge currents flew in the time period around the maximum voltage and stopped after that. The integral of the inner area indicated that the electric power consumed in the discharges and summed up in all microbubbles was $0.91 \mathrm{~W}$.

Discharge emission was investigated using a monochromator equipped with an intensified charged-coupled device as a detector array (Princeton Instruments, I-MAX-1024-E). Detected spectra from emission in hydrogen bubbles are shown in Fig. 4(a) at $4.0 \mathrm{kV}_{0 \mathrm{p}} . \mathrm{H}_{\alpha}(656 \mathrm{~nm})$ and

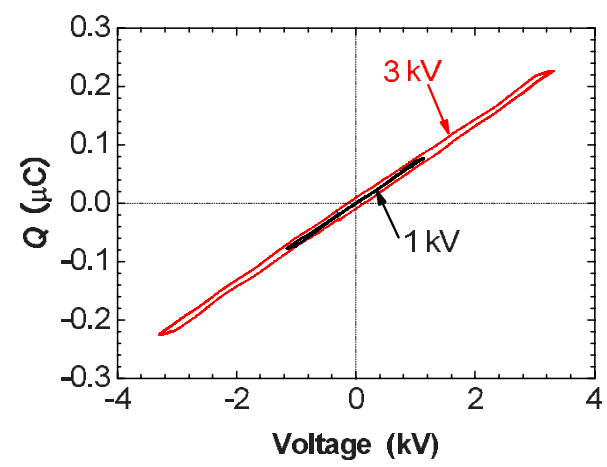

FIG. 3. (Color online) Accumulated charge on dielectric barriers $Q$ as a function of applied voltage.

$\mathrm{H}_{\beta}(486 \mathrm{~nm})$ lines were clearly observed, which indicated that hydrogen microplasmas formed. The continuous spectrum throughout the measured range arises from $\mathrm{H}_{2}$ molecules. In the case of oxygen bubbles with the applied voltage of $4.0 \mathrm{kV}_{0 \mathrm{p}}$, as shown in Fig. 4(b), an atomic oxygen line at $777 \mathrm{~nm}$ was observed. These facts show that, using hydrogen and oxygen bubbles generated in electrolysis, hydrogen and oxygen plasmas were generated in the regime of dielectric barrier discharges, and hydrogen and oxygen atoms were present in a certain amount.

To evaluate net transport of $\mathrm{H}$ atoms and/or $\mathrm{H}^{+}$(or $\mathrm{H}_{3} \mathrm{O}^{+}$) ions into the solution contributing to the increase in $\mathrm{H}_{3} \mathrm{O}^{+}$ion concentration $\left[\mathrm{H}_{3} \mathrm{O}^{+}\right]$, we performed $p \mathrm{H}$ measurements of the solutions that contained hydrogen bubbles with hydrogen microplasmas on the wires and oxygen bubbles without oxygen plasmas. Activity of $\mathrm{H}^{+}$(or $\mathrm{H}_{3} \mathrm{O}^{+}$in more precise expression) in solution, $a_{\mathrm{H}^{+}}$, which is approximately $\left[\mathrm{H}_{3} \mathrm{O}^{+}\right]$in ideal-dilute behavior, is expressed using the activity of $\mathrm{OH}^{-}$in solution $a_{\mathrm{OH}^{-}}$as $a_{\mathrm{H}^{+}} a_{\mathrm{OH}^{-}}=K_{\mathrm{w}}$, where $K_{w}\left(=1.0 \times 10^{-14}\right)$ is the autoprotolysis constant or ion product of water, and the activities are in the unit of mol dm${ }^{-3}$. Here the meaning of "net" transport indicates combined effects including increase in $\left[\mathrm{H}_{3} \mathrm{O}^{+}\right]$by $\mathrm{H}$ atoms and/or $\mathrm{H}^{+}$ ions and decrease in $\left[\mathrm{H}_{3} \mathrm{O}^{+}\right]$by the equilibrium with $\left[\mathrm{OH}^{-}\right]$.

In electrolysis, a direct current of 0.05 A flowed for 10 min without imposition of discharge voltage, and a period of

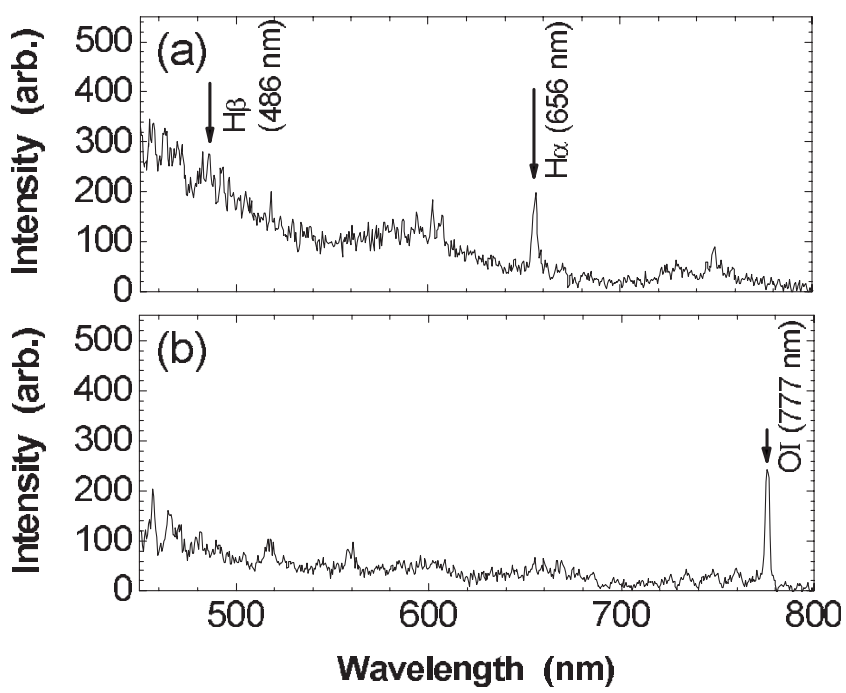

FIG. 4. (a) Emission spectrum of microplasmas in hydrogen microbubbles. (b) Emission spectrum of microplasmas in oxygen microbubbles. 


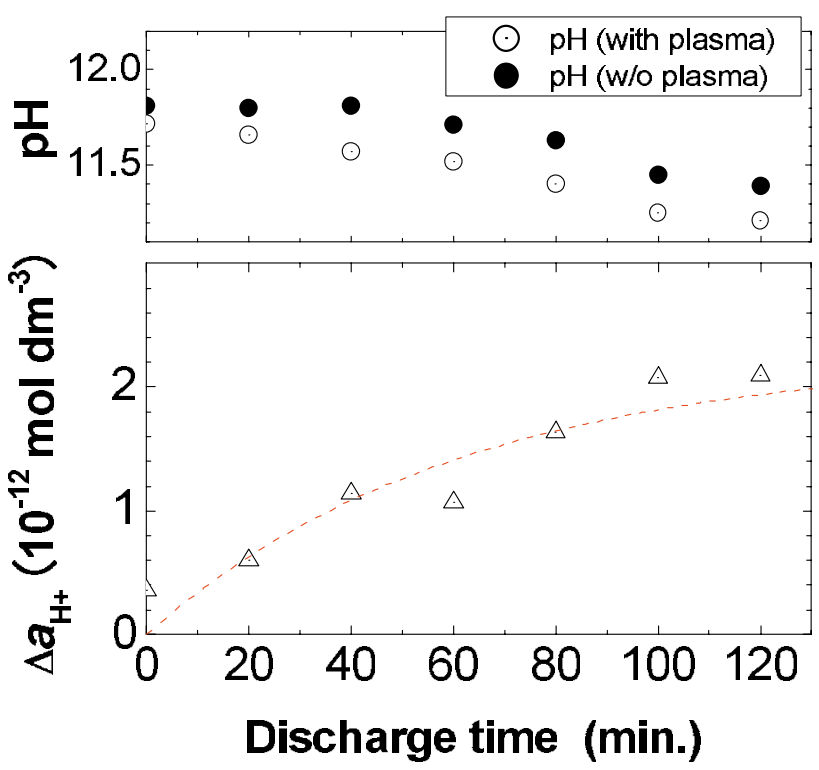

FIG. 5. (Color online) Time evolutions of $p \mathrm{H}$ in cases with and without microplasma generation in hydrogen microbubbles and difference of activity in $\mathrm{H}^{+}$between two cases. The dotted line is plotted as an exponential function of time.

plasma generation followed for $20 \mathrm{~min}$ at a discharge voltage frequency of $10 \mathrm{kHz}$ after the electrolysis was turned off, and then the aqueous solution $\left(80 \mathrm{~cm}^{-3}\right.$ in volume with $\mathrm{Na}_{2} \mathrm{CO}_{3}$ in $1 \mathrm{wt} \%$ ) was transferred to a $p \mathrm{H}$ measurement system (HORIBA F-52, Horiba Inc.); this series of treatment was repeated during this experiment. The discharge voltage at $3 \mathrm{kV}_{0 \mathrm{p}}$ was applied only on the insulated-wire electrodes, which were surrounded by the conductive solution, and so no additional electrolysis by this voltage imposition took place, which was verified by constant size of the microbubbles. Figure 5 shows the time variation in $p \mathrm{H}$ values in the cases with and without hydrogen plasma generations. We monitored significant difference in the $p \mathrm{H}$ values between these two cases.

Figure 5 also shows difference in $a_{\mathrm{H}^{+}}\left(\right.$or $\left.\left[\mathrm{H}_{3} \mathrm{O}^{+}\right]\right)$increased by hydrogen microplasma generation $\Delta a_{\mathrm{H}^{+}} \Delta a_{\mathrm{H}^{+}}$became large in the initial phase and saturated after $80 \mathrm{~min}$ in process. This saturation phenomenon might be reflected by faster reactions of $\mathrm{H}$ atoms and $\mathrm{H}^{+}$ions generated by microplasmas than $\mathrm{H}_{2}$ molecules that are present in the cases without microplasma generation. To conserve charge neutrality, an $\mathrm{H}^{+}$ion and an electron are simultaneously transported into solution. $\left[\mathrm{H}_{3} \mathrm{O}^{+}\right]$directly affects the $p \mathrm{H}$ value as $\mathrm{H}_{3} \mathrm{O}^{+}$ $+\mathrm{OH}^{-} \rightleftarrows 2 \mathrm{H}_{2} \mathrm{O}$. A solvated electron $e_{\mathrm{aq}}^{-}$, working as a reductant, and an $\mathrm{H}$ atom are converted into $\mathrm{OH}^{-}$by the diffusioncontrolled reaction as

$$
\mathrm{e}_{\mathrm{aq}}^{-}+\mathrm{H}+\mathrm{H}_{2} \mathrm{O} \rightarrow \mathrm{OH}^{-}+\mathrm{H}_{2},
$$

in addition to the reaction as $2 \mathrm{e}_{\mathrm{aq}}^{-}+2 \mathrm{H}_{2} \mathrm{O} \rightarrow 2 \mathrm{OH}^{-}+\mathrm{H}_{2}$. Such an $\mathrm{OH}^{-}$ion makes $\left[\mathrm{H}_{3} \mathrm{O}^{+}\right]$in equilibrium after a transient phase. Additional factor by a transported $\mathrm{H}$ atom is $\mathrm{H}_{2} \mathrm{O}_{2}$ formation with reactions of $\mathrm{O}_{2}$ naturally solved in water, leading to a further increase in $\left[\mathrm{H}_{3} \mathrm{O}^{+}\right]$. On the other hand, $\mathrm{H}_{2}$ molecules are in equilibrium according to the similar reaction in the standard hydrogen electrode as

$$
\mathrm{H}_{2}+2 \mathrm{H}_{2} \mathrm{O} \rightleftarrows 2 \mathrm{H}_{3} \mathrm{O}^{+}+2 \mathrm{e}_{\mathrm{aq}}^{-} .
$$

These differences of reaction schemes might give rise to faster saturation of microplasma effects on $\left[\mathrm{H}_{3} \mathrm{O}^{+}\right]$; production of $\mathrm{H}^{+}$ions and electrons enhances $\left[\mathrm{H}_{3} \mathrm{O}^{+}\right]$in the solution and the following reaction (1) hastens saturation of $\Delta a_{\mathrm{H}^{+}}$.

Other reactions of $\mathrm{H}$ atoms with other solutes, such as $\mathrm{CO}_{3}^{2-}$, may affect the $p \mathrm{H}$ value. These effects are also larger than reaction (2) and might be involved in $\Delta a_{\mathrm{H}^{+}}$shown in Fig. 5. We also note that another source of change in the $p \mathrm{H}$ value without hydrogen microplasma generation may be unbalanced solubility of hydrogen and oxygen molecules in bubbles with different surface areas on the cathode and anode electrodes of the electrolysis.

One of the significant advantages of hydrogen plasma generation in solution is abstraction and addition reactions of $\mathrm{H}$ atoms. ${ }^{7}$ When they abstract an $\mathrm{H}$ atom from a solute $R \mathrm{H}$ as $\mathrm{H}+R \mathrm{H} \rightarrow R+\mathrm{H}_{2}$, successive reactions triggered by free radicals $R$ will take place. When an $\mathrm{H}$ atom is added to an unsaturated system like benzene, other kinds of successive reactions will take place. That is, $\mathrm{H}$ atoms, of which presence was convinced by the $\mathrm{H}_{\alpha}$ spectrum, are possibly generated much more than $\mathrm{H}^{+}$ions and enhance the chemical reactions in aqueous solutions. Similarly, in the case of oxygen bubbles, produced oxygen atoms are also very reactive to induce various chemical reactions in solutions. ${ }^{3}$

In summary, experimental results on hydrogen and oxygen microplasmas were demonstrated, and these two kinds of gas bubbles were selectively prepared through a simple electrolysis system. This scheme enables us to be free from gas containers for plasma generations in aqueous solutions. Thanks to the fabric-type electrode, positions of microbubbles were controlled. The monitored tendency of $p \mathrm{H}$ values showed enhancement in $\left[\mathrm{H}_{3} \mathrm{O}^{+}\right]$by microplasma generation in hydrogen microbubbles, which will trigger enhancement of chemical reactions by plasmas in solutions.

This work was supported in part by the Grants-in-Aid for Scientific Research from the Japanese Ministry of Education, Culture, Sports, Science, and Technology.

\footnotetext{
${ }^{1}$ A. A. Joshi, B. R. Locke, P. Arce, and W. C. Finney, J. Hazard. Mater. 41, 3 (1995).

${ }^{2}$ M. Kurahashi, S. Katsura, and A. Mizuno, J. Electrost. 42, 93 (1997).

${ }^{3}$ P. Lukes and B. R. Locke, J. Phys. D 38, 4074 (2005).

${ }^{4}$ M. Kimura, T. Shirafuji, O. Sakai, and K. Tachibana, Proceedings of the 18th International Conference on Plasma Chemistry (Kyoto, Japan, 2007), p. 59.

${ }^{5}$ O. Sakai, T. Shirafuji, and K. Tachibana, Proceedings of 18th International Conference on Plasma Chemistry (Kyoto, Japan, 2007), p. 208.

${ }^{6}$ O. Sakai and K. Tachibana, J. Phys.: Conf. Ser. 86, 012015 (2007)

${ }^{7}$ K. U. Ingold, in Free Radicals, edited by J. K. Kochi (Wiley, New York, 1973), p. 82.
} 